\title{
The Realistic Variables Underlying True Safety in Tattoo Pigment Manufacturing
}

\author{
Mario Barth \\ INTENZE Products, Hackensack, N.J., USA
}

\begin{abstract}
The regulation of the manufacture of tattoo ink products in the USA and the rest of the world is the focus of this article, which outlines the historical relationships between official and unofficial manufacturing and associated regulations, self-regulating movements within the industry and the impacts of over-regulation on the economics of ink manufacturing markets. The author, Mario Barth, highlights that changes in industry standards of production that are too rapid can cause the system to deteriorate, leading to an essentially negative shift to the underground markets. In addition, these regulations would not lead to a healthier end product because the currently considered health problems associated with tattoos (affecting $6 \%$ of tattoos performed in Germany) could be caused by multiple additional factors, such as the tattooing technique and aftercare. The pigment itself (which causes health issues in only $0.6 \%$ of tattoos) could in this equation not be optimized within an overregulated market. Further, aspects of price and revenue are analyzed in detail, showing that high quality suppliers are spending most of their efforts on passing regulations and that these regulations are not decreasing the amount of low-quality products in the general market. Finally, the notion of tattooing as 'an adult decision' is explained as another variable that has to be considered in creating regulations because the decision-making process for a
\end{abstract}

tattoo (considering the price, quality and definitely the permanency) has and will have a self-regulating impact driven by the clients.

(C) 2015 S. Karger AG, Basel

To be perfectly clear before I start, I just want to say that I am not at all opposed to the regulation of tattoo pigments. However, I do believe that there are many variables to the equation and that over-regulating pigment manufacturing is just as dangerous as having no regulations or guidelines at all. The ResAP/2008, in its original form, led to massive changes in tattoo pigment manufacturing. Tattoo pigment manufacturers are still trying to comply with these regulations as new restrictions are put in place overnight. For an inside view from the perspective of a tattoo pigment manufacturer, please continue reading.

To properly understand why the tattoo pigment manufacturing industry is welcoming proper regulation and recognizes its importance, we need to look at tattoo pigment manufacturing historically. Pigment manufacturing is as old as tattooing itself. In the beginning, pigments were merely produced by the performing artist, and they have been prepared in this way until recently. 
The following quote is from a 1925 Percy Waters catalog, in which he talks about his pigment [1]:

'Use only the best colors purchased from reliable dealers. They are chemically pure and harmless to the skin, while imitation colors sold by so-called importers, are nothing more than common house paint, and likely poison. Genuine colors are seldom found among the beginners, as they, not knowing the difference, use what they are told, or perhaps buy them at a far higher price. The best colors are used by the OLD TIME TATTOOERS, who know the kind to buy as well as they know a bright colored tattoo will bring them business.'

Although it can be strongly argued that the colors used during this time period were safe and harmless and that only old-timers had knowledge of the best colors to use, this quote shows, in documented form, that the industry began to self regulate and consider product safety almost 100 years ago. It also raises a more interesting point, which can be recognized by sitting back and reading more closely between the lines, about the real issue related to the connections between artists' qualifications, supplies, knowledge and proper tattoo pigments. It is very clear that even during this early time of professional tattooing and pigment manufacturing, the educational level of the performing artist played a significant role in the behavior of the pigments. To date, not much has changed with the use of imitation colors, which are mostly produced by 'underground' tattoo pigment manufacturers. These imitation colors are used primarily but not exclusively by 'underground' or beginner tattoo artists, who out-number the professionals.

Some can argue that this is one more reason for the upcoming regulations, which aim to promote the safety of the end consumer, and they may be correct; however, the sole challenge remains in regulation which is a combination of product, education, proper use of material and the vital aftercare by the client of the tattoo, this is not considered or even remotely addressed. To state this issue as an example, a car is built with no tires, and it is placed on wooden blocks. It does not matter how great the interior and engine are, the vehicle will remain motionless, and people will walk rather than use it for its intended purpose of transportation.

It is a commonly known fact in the tattoo industry that tattoo artists, pigment manufacturers, and tool manufacturers and suppliers will and do selfregulate, and they have done an exceptional job at it over the past hundred or so years with no help from the regulating agencies. However, this does not mean that there should be no regulations; in fact, it suggests the complete opposite. It merely shows that arguably, it will be necessary to work closely together and to understand that a craft that is a thousand years old cannot be changed in a couple of years, especially by regulating pigments without truly understanding the global impact, training needed for the industry, economic feasibility, qualified control, targeted and proper enforceability and more importantly, sustainability. It does not help to regulate one part of the equation and not consider the equally important counterpart and then expect a sustainable outcome. To clarify this in more detail, consider whether it is possible to lose 40 kilos or pounds in 1 day. Although it seems impossible, it is achievable by severing all of the limbs and the head. Although it is very clear that the weight loss was accomplished, life will no longer be sustained. Thus, it is of the upmost importance to consider all variables before making a decision based solely on a theoretical thought process. Considering the example above, one outcome would ultimately result in the loss of life. It would be an easier and ultimately better choice to lose this weight over an extended period of time, which represents a healthier alternative associated with a lifestyle change. Similarly, the regulation of tattoo pigment manufacturers needs to be implemented over a significant period of time to ensure sustainability, achievable measures and the ability for all manufacturers to comply without jeopardizing the health and safety of the end consumer while still keeping a sufficient number of licensed and qualified art- 
ists. The enforcement of these regulations in an extreme fashion does not provide quality pigment manufacturers with enough time to make proper changes, giving underground artists, who lack regulations and are thus more likely to cause health concerns that are not traceable and are more difficult to treat, a chance to take over the industry. Although it seems logical to enforce stringent regulations on pigments for tattooing, without the training of artists and the education of the end consumer on the importance of aftercare, these regulations will actually achieve the opposite of their desired effects. One must understand that every human being who receives and applies these pigments and the clients taking care of the finished tattoo have many very different ways of doing so, creating countless combinations of variables. This issue also becomes very clear when a person experiences a possible reaction to a pigment.

It may be very interesting to analyze this issue. Key indicators must be examined, including how many reactions can be traced back to improper supplies, application and aftercare, and it is always easiest find fault with the pigment. Human nature makes it easy to place the blame on a product instead of considering that proper pigment use and care is equally important.

A study performed at the University of Regensburg on health problems associated with tattooed skin indicated that $6 \%$ of tattooed persons reported persistent health problems after receiving their first tattoo. On average, these persons had two to three tattoos [2], which reduces this figure [3] to $2.6 \%$ reactions per tattoo received.

In a follow-up report, Professor Richard White from the University of Worcester [4] suggested that there are four causes of adverse dermatological effects besides allergic reactions - the techniques, the instruments (needles and machines), the aftercare and the ink products.

This means that if weighted with the same importance, only $0.65 \%$ of reactions related to the $1,000,000+$ tattoos done yearly in Germany have direct correlations with the ink product used.
Allergic and intolerance reactions are not separately considered within that $0.65 \%$ because they have been recently identified as the biggest contributors to personal hygienic product reactions by the German 'Industrie-Verband für Körperpflege.' This could be considered to be an additional factor disputing the 'authentic' health problems caused by tattooing pigments.

This research has provided further clarification that the over-regulation of tattoo pigments is questionable. Especially considering how time and cost intensive these changes are for manufacturers and government regulatory agencies, even more concerns are raised by analyzing the possible peak point at which a qualitative regulation becomes such an overburden that it triggers a decline in manufacturing, and it becomes easier to create uncontrolled underground pigments.

Let's take a look at another factor, the pricing structure of the industry itself. The current professional pigments per $30 \mathrm{ml}$ are priced in the range of EUR 9.00-14.00. Research in the industry has shown that the most common bottle size in use is $30 \mathrm{ml}$. Quality pigment manufacturers are working very hard to deliver a product that is high quality with health and safety in mind, whereas others are more concerned with reaching the masses with a product that is lower in quality but has a higher profit margin. The retail cost of the same $30-\mathrm{ml}$ bottle is the same in the 'underground' market; however, the profit margin is significantly higher, and manufacturers choose not to follow regulations, even going so far as to not label or to continuously rename a product. Current raw pigment prices have risen, and some have even increased from USD 5.00-75.00 per pound. The biggest variable, however, is the retail price, which has not changed in 25 years, leaving quality manufacturers battling with very tight margins.

Disturbingly, the legislative system focuses more on over-regulating already quality-driven companies with new, unexplained pigment prohibitions instead of creating a unified, controlled enforcing and testing system in Europe. 
This situation is akin to illegal immigration. Making it harder to immigrate legally does not make illegal immigrants stop because they have no intention of being legal anyway. It just causes them to find different ways to enter into foreign countries without detection.

A very unique challenge arises in changing these prohibited pigment lists. First, without the proper documentation of several years' worth of research on the dangers of tattooing by regulating agencies, there is no clear guideline to follow. Second, there is no list of permitted pigments, which forces manufacturers to guess what they can use next. To understand the complexity of this issue in terms of production and mixing, it is necessary to consider the limited number of base pigments, which are worked into more than 200 different shades of color.

Every time there is a change in a pigment requirement for a single color, it takes approximately 6-12 months until tattoo pigment manufacturers can truly comply.

Consider the following example:

Step 1: The tattoo pigment manufacturer is informed of a new item on the prohibited list (which has received prior approval and now has been changed). It has to be understood that this information is not currently communicated proactively; instead, the manufacturer has to comply reactively because there is no proper pre-informative channel between legislative agencies and manufacturers. At this moment, it is a code-red situation, and the manufacturer has to decide which of the items in research and development could be used as a replacement. Most well-established manufacturers do preliminary testing on skin with different available pigments that are not on the prohibited list.

Step 2: The owners themselves typically act as test subjects in these cases to avoid conflicts. Let's assume that one pigment is available that is ready to be used and is not on the ban list. It will have to be sent to a third party laboratory to pass all of the regulations, which will have a turnaround of
4-6 weeks. If the sample passes, it will be ready to be intermixed with all possible shades.

Step 3: At this time, it will take at least 6 weeks to recreate shades of colors that have been previously used. It is of the upmost importance that colors are matched properly because the end consumer will be unable to make changes to the final product after it is tattooed into the skin. Neverending variables and possibilities start to arise again. Different countries have different inhabitants with a variety of skin conditions depending on the environment (e.g. the temperature or level of sun exposure) and a wide range of skin tones, and variations in healing conditions and artist education may also be present. The manufacturer has to perform tests on several subjects, who are in most cases the owner and/or very close relatives of the company. Who else would run the risk of the permanent color changing after healing to something less desirable than expected?

Step 4: This process alone (from receiving the tattoo to its complete healing) takes a minimum of 12 weeks!

Step 5: If the pigment is now ready to be part of the full production schedule, companies must create many different shades. Let's assume that a yellow pigment is changed. There will be between 40 and 80 color tones that must be re-formulated, and the desired inventory must be created. In the real world of manufacturing, only $30 \%$ of companies worldwide can create more than 10 shades of colors per day effectively, and even more importantly, in sufficient volumes, after which they have to be labeled and packaged in many different languages, according to the requirements of the laws of each individual country. Thus, even in the best case in which everything works well, it will take a minimum of 24 weeks (yes, almost 5-6 months) to make the proper changes.

There is another factor to be considered, which is the permanency of the pigments. It should never be forgotten that a tattoo is meant to be permanent and not temporary. People with no tattoos always seem to have concerns about what happens 
when a tattooed person ages and whether he or she will regret the decision to become tattooed. It is of the utmost importance to realize that it is very well known in the industry that when a person decides to receive his or her first tattoo, he or she has thought about it and researched it before deciding to fully commit to permanently changing his or her body. In today's age, the myth of the drunken sailor stumbling into a dark back corner and getting tattooed from some stranger, waking up the next morning with a tattoo on his arm that he did not want is outdated. In the same way, people no longer have to ride a horse to get from $\mathrm{New}$ York to California. Times have changed and people have evolved. Most people who receive a tattoo in 2014 will choose a design, agree to its placement on their body, and then get through the somewhat painful and timely process of tattooing in addition to the lengthy healing process afterwards. To assume that a person receiving this mark out of his or her own free will and decision made a mistake is of great ignorance to the fact that people differ and make their own choices.

Now, why is it so important to understand the challenges for regulating the tattoo pigment industry? Why should it be of concern? Well, some could argue that it is not important, but it is extremely critical to understand the economics of tattooing at the professional versus underground level. A statistical verification by the Pew Research Center dated 12.11.2013 mentions that the average cost of a professional tattoo is USD 45.00 (EUR 35.00) [5]. The same tattoo performed underground would cost USD 25.00 (EUR 19.00). This is where the trouble starts, considering the other factors in the calculation. Let's assume that both of the artists have to pay for their supplies and rent a place of business; however, one will be controlled and one will not, one will be trained and one will not, and one will use higher quality supplies, and the other will not.

The consumer decides who will do his or her tattoo. Yes, it is still an adult decision. It is no less of an adult activity than drinking a beer or having a cigarette and most likely, there is less of a chance of injury or even death. Both beer and cigarettes are very well regulated and both have risks, as does the act of getting tattooed. The industry itself is pushing to create more awareness of choosing properly trained artists, thereby lowering the risk of complications arising after the tattoo is finished to a figure even lower than the $2.6 \%$ stated above. Not bad for a self-regulated industry that nobody cared about 5 years ago. It will be of great necessity to include proper training, supplies and aftercare for effective regulation.

The financial impact of the past 10 years on pigment manufacturing has been dramatic if not already close to devastating. Five years ago, most pigments were created in basements, kitchens and garages, and $60 \%$ still are (remember the immigration example?). Today, leading companies have facilities with internal laboratories and cleanrooms. They follow the label requirements of the US Food and Drug Administration and make daily changes to better their products. Good manufacturing practice is standard, as is the traceability of products. The main manufacturers are proactively trying to get updated information from regulating authorities so that they can provide the necessary quality products and abide by new laws. This may not sound like a regulatory problem, but it will be when this industry deteriorates and loses another quality manufacturer to draconian regulations, which currently may be responsible for the pigment reactions of less than 1 PERCENT of persons getting tattooed this year. We all would love to have $0 \%$ risk. Unfortunately, it is not possible. Considering that most manufacturers are willing and happy to conform with upcoming regulations and that they all agree on the concerns and dangers, their rates of implementation cannot be determined without the discussion of all quality pigment manufacturers as well as regulatory agencies. Going further, it must be considered that most regulations will not be economically technically achievable outside of theory in a laboratory. In real production scenarios, industry could be forced right back to where it 
feels comfortable and where it will remain for another 1,000 years. These events will occur for the following reasons: some of the new proposed raw pigments are way too high in price, the color shades are completely prohibited, they are not readily available in the amounts needed, and they may not conform with the tattoo industry standard of permanency (that the color will stay the same shade under the skin after healing). Another factor to consider is that the price of a $30-\mathrm{ml}$ bottle would need to increase significantly, forcing artists to find an alternative and cheaper source. At this point, there is no proposal explaining how the government will supplement the research and development to make an improved product for the better health and safety of the end consumer. A grant or some kind of assistance would possibly make this transition feasible. In addition, how will the government enforce the purchasing of tattoo pigments through licensed and regulated tattoo pigment manufacturers (including purchases made by unlicensed tattoo artists and shops)?

In conclusion, there are many factors and variables that need to be taken into consideration before such stringent laws and regulations are enforced and must be followed by quality manufacturers. Changes to regulations and laws are creating a safer environment every day for the manufacturer and end consumer, they just need to be carried out with sufficient time to make them reasonable to achieve and more importantly, to sustain on a continuous basis. Ultimately, ResAP/2008 was a great regulation in its original form. Many color companies are still working today to create an environment in which this regulation can be achieved. Many newly proposed updated and implemented additions to the original regulation have only led to ongoing chaotic changes, and they have also had dramatic negative effects on sustainability. Many companies that are willing to make changes to improve the tattoo pigment industry have taken on great financial strain to provide better conditions for the end consumer and an improved product according to ResAP/2008. With the ongoing inconsistency of unified testing methods, which is still the GIANT ELEPHANT in the room throughout Europe, in addition to the other variables mentioned, there is still a lot to be done before this is to be advocated and drastic changes are made. Currently, the odds are not in favor of the willing players in this highly important undertaking, which aims to improve the health and safety of the general public at large. One thing that we can all agree upon is that the health and safety of the person(s) getting tattooed as well as the survival of professional tattoo artists and pigment manufacturers are the most important factors.

\section{References}

1 McKay EC: Pigment. 2011. http://www. tattooarchive.com/tattoo_history/ pigment.html.

2 Klügl I, Hiller KA, Landthaler M, Bäumler W: Incidence of health problems associated with tattooed skin: a nationwide survey in German-speaking countries. Dermatology 2010;221:43-50.
3 Market Research Interpretation/Intenzive Marketing International/2014. $' \mathrm{~N}=3000->6 \%=180$ indicating tattoos I $\mathrm{N}=3000 * 2,3=6900$ Tattoos done on the requested persons - 180 tattoos of $6900=2,6 \%$ '.
4 Wright R: Tattoos as wounds: a clinical efficacy study of two aftercare preparations. Wounds UK 2012;8:32-40.

5 Statistic Brain: Tattoo statistics. 2013. http://www.statisticbrain.com/tattoostatistics/.

Mario Barth

Intenze Products

15 Van Orden Place

Hackensack, NJ 07601 (USA)

E-Mail mb@starlighttattoo.com 